\title{
THEORETICAL STUDIES ON THE STRUCTURAL PROPERTIES OF 2,3-BIS(FURAN-2-YL)PYRAZINO[2,3-F][1,10]PHENANTHROLINE
}

\begin{abstract}
Z. Sadeghian
Department of Chemistry, Faculty of Science, Imam Khomeini International University, Qazvin, Iran E-mail: sadeghianzahra421@yahoo.com

Received July, 16, 2015

This paper reports the optimized geometrical parameters of the stationary point for 2,3bis(furan-2-yl)pyrazino[2,3-f][1,10]phenanthroline. The calculations are performed using the density functional theory (DFT) method at the B3LYP/ LanL2DZ level. Bond lengths and bond angles are determined for the compound and the amount of bond hybridization is calculated according to the natural bond orbital theory (NBO). The energy of frontier orbitals (HOMO and LUMO) are computed. In addition, the calculated data are accurately compared with the experimental results. This comparison shows that our theoretical data are in reasonable agreement with the experimental values.
\end{abstract}

DOI: $10.15372 / \mathrm{JSC} 20150709$

K e y w o r d s: 2,3-bis(furan-2-yl)pyrazino[2,3-f][1,10]phenanthroline, density functional theory, theoretical calculations, LanL2DZ level, B3LYP level.

\section{INTRODUCTION}

2,3-Di(furan-2-yl)pyrazino[2,3-f][1,10]phenanthroline $\mathrm{C}_{22} \mathrm{H}_{12} \mathrm{~N}_{4} \mathrm{O}_{2}$ has a rigid structure and fluorescence properties. Due to these features it has been extensively used as a ligand in both analytical and preparative coordination chemistry. Single crystals were obtained by recrystallization from the mixture of methanol and dichloromethane at room temperature [1,2].

1,10-Phenanthroline or $o$-phenanthrolin (phen) as one of the starting materials for the synthesis of the mentioned compound is a tricyclic aromatic hydrocarbon composed of three fused benzene rings having five resonance structures (isomeric with anthracene). This white crystalline powder soluble in organic solvents is the parent of an important class of chelating agents and is used as a versatile ligand in coordination chemistry. In terms of its coordination properties, phen is similar to 2,2'-bipyridine (bipy). Phen has a rigid structure imposed by the central ring, which means that two nitrogen atoms are always held in juxtaposition, whereas in bipy free rotation about the linking bond allows the two nitrogen atoms to separate, in particular, under basic or strongly acidic conditions. These phen advantages mean that complexes with metal ions can form more rapidly [3, 4 ].

1,10-Phenanthroline is an inhibitor of metallopeptidases, with one of the first observed instances reported in carboxypeptidase and used as an oxidation-reduction indicator to determine iron due to characteristic color changes (turning faint blue when oxidized). Cholinergic agent, cholinesterase inhibitor, intercalating agent, cross-linking reagent, neurotransmitter agent, starting material to prepare dyes and drugs are the other usages of this compound. It is used in metallocene industry for some applications such as catalysts for the oxidative organic synthesis, disease diagnosis and treatment, water treatment, photolysis chemistry and microbiology [5]. These varied properties and applications of phen motivated us to investigate the structures and properties of the titled compound that includes phen.

(C) Sadeghian Z., 2015 
<smiles>c1coc(-c2nc3c4ncccc4c(-c4ccco4)nc3c3ncccc23)c1</smiles>

Fig. 1. Name and molecular structure of the titled compound

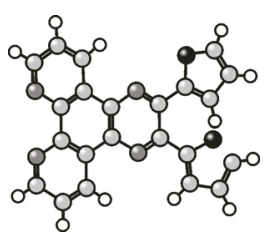

Fig. 2. Optimized structure of the titled compound (ball and stick model) at the B3LYP/LANL2DZ level of theory

In the present paper we report the results of the geometrical optimization at the DFT (B3LYP) level employing the LanL2DZ basis sets, using the Gaussian 09 program. The theoretical data are compared with experimental values. The natural bond orbital analysis is performed in this work. These studies allow us to know about the type of orbitals and the percentage of the $s$ - and $p$-type character. The energies of HOMO and LUMO are calculated [6 ].

\section{METHODS}

B3LYP, a version of the DFT method with the use of Becke's three-parameter hybrid method with the Lee, Yang, and Parr (B3LYP) gradient corrected correlation functional and the LanL2 effective core potential with the $\mathrm{DZ}$ valence basis set, was used in this paper to carry out theoretical calculations. Then, the geometry optimization was carried out at the B3LYP/LanL2DZ level. The natural bond orbital analysis has also been performed at the B3LYP/LanL2DZ level. The energies of the frontier orbitals (HOMO and LUMO) are determined. All computations are carried out using the Gaussian 09 program [ 7-12].

\section{RESULTS AND DISCUSSION}

Molecular properties. The chemical and optimized structures of the compound are presented in Figs. 1 and 2 respectively. Molecular parameters can be extracted from the optimized structure of the compound. Molecular parameters can provide a useful representation of the molecular structure. Therefore, we extracted bond lengths and bond angles of the computed compound. The calculated data and experimental values of some selected bond distances and angles are reported in Table 1.

The results of the calculation at the B3LYP/ LANL2DZ level show that the calculated $\mathrm{C}_{2}-\mathrm{N}_{3}$, $\mathrm{C}_{4}-\mathrm{N}_{3}, \mathrm{C}_{1}-\mathrm{N}_{6}$, and $\mathrm{C}_{5}-\mathrm{N}_{6}$ bond distances are the same, indicating the pyrazine ring conjugation. This value is $1.348 \AA$. Experimental $\mathrm{C}_{2}-\mathrm{N}_{3}, \mathrm{C}_{5}-\mathrm{N}_{6}, \mathrm{C}_{4}-\mathrm{N}_{3}$, and $\mathrm{C}_{5}-\mathrm{N}_{6}$ bond distances are $1.331 \AA$ and $1.349 \AA$ respectively. The calculated $\mathrm{N}_{3}-\mathrm{C}_{4}-\mathrm{C}_{7}, \mathrm{C}_{5}-\mathrm{C}_{4}-\mathrm{C}_{7}, \mathrm{C}_{8}-\mathrm{C}_{7}-\mathrm{O}_{11}, \mathrm{C}_{7}-\mathrm{C}_{8}-\mathrm{C}_{9}$, and $\mathrm{C}_{2}-\mathrm{C}_{1}-\mathrm{N}_{6}$ bond angles are $113.34^{\circ}, 124.67^{\circ}, 110.08^{\circ}, 106.64^{\circ}$, and $121.87^{\circ}$ respectively. Experimental bond angles are $114.81^{\circ}, 124.31^{\circ}, 110.11^{\circ}, 106.52^{\circ}$, and $121.21^{\circ}$ respectively. The average differences between the calculated data and the experimental values for bond lengths and bond angles are $0.009 \AA$ and $0.53^{\circ}$. This comparison shows that our theoretical data are in good agreement with the experimental results.

Optimized geometrical parameters of the compound (bond distances in $\AA$, angles in deg.)

\begin{tabular}{l|c|c||c|c|c}
\hline Parameter & Calculated data & Experimental value & Parameter & Calculated data & Experimental value \\
\hline $\mathrm{C}_{1}-\mathrm{N}_{6}$ & 1.348 & 1.349 & $\mathrm{C}_{2}-\mathrm{C}_{1}-\mathrm{N}_{6}$ & 121.87 & 121.21 \\
$\mathrm{C}_{2}-\mathrm{N}_{3}$ & 1.348 & 1.349 & $\mathrm{~N}_{3}-\mathrm{C}_{4}-\mathrm{C}_{7}$ & 113.34 & 114.81 \\
$\mathrm{C}_{4}-\mathrm{N}_{3}$ & 1.348 & 1.331 & $\mathrm{C}_{5}-\mathrm{C}_{4}-\mathrm{C}_{7}$ & 124.67 & 124.31 \\
$\mathrm{C}_{4}-\mathrm{C}_{5}$ & 1.419 & 1.429 & $\mathrm{C}_{4}-\mathrm{C}_{5}-\mathrm{N}_{6}$ & 121.87 & 120.91 \\
$\mathrm{C}_{4}-\mathrm{C}_{7}$ & 1.722 & 1.463 & $\mathrm{C}_{1}-\mathrm{N}_{6}-\mathrm{C}_{5}$ & 116.24 & 117.71 \\
$\mathrm{C}_{5}-\mathrm{N}_{6}$ & 1.348 & 1.331 & $\mathrm{C}_{4}-\mathrm{C}_{7}-\mathrm{O}_{11}$ & 100.70 & 117.81 \\
$\mathrm{C}_{7}-\mathrm{O}_{11}$ & 1.395 & 1.371 & $\mathrm{C}_{8}-\mathrm{C}_{7}-\mathrm{O}_{11}$ & 110.08 & 110.11 \\
$\mathrm{C}_{8}-\mathrm{C}_{9}$ & 1.448 & 1.421 & $\mathrm{C}_{7}-\mathrm{C}_{8}-\mathrm{C}_{9}$ & 106.64 & 106.52 \\
$\mathrm{C}_{10}-\mathrm{O}_{11}$ & 1.395 & 1.368 & $\mathrm{C}_{7}, \mathrm{O}_{11}, \mathrm{C}_{10}$ & 106.56 & 105.91
\end{tabular}


Fig. 3. Atomic orbital of the frontier molecular orbital at the B3LYP/LanL2DZ level. $(A)$ is the HOMO and $(B)$ is the LUMO

Frontier molecular orbitals (FMOs). A powerful practical model for describing the chemical reactivity is the frontier molecular orbital (FMO) theory. The important aspect of the frontier electron theory is the focus on the highest occupied and lowest unoccupied molecular orbitals (HOMO and LUMO). For example, instead of thinking about the total electron density in a nucleophile, we should think about the localization of the HOMO because electrons from this orbital are most free to participate in the reaction. Similarly, the frontier orbital theory predicts that a site where the LUMO is localized is a good electrophilic site.

A quantum chemical parameter which is often associated with the electron donating ability of the molecule is $E_{\text {номо }}$. A high


trons to the appropriate acceptor molecule with a low molecular orbital energy [ 13 ]. Therefore, the LUMO energy $E_{\text {LUMO }}$ indicates the ability of the molecule to accept electrons. These two energy types are calculated at the LanL2DZ level. The energy difference between the HOMO and LUMO is termed the HOMO-LUMO gap. Fig. 3 demonstrates these energies and 3D plots of HOMO and LUMO for the compound.

Natural bond orbital (NBO) analysis. The NBO analysis is based on the optimal transformation of a given wave function to the localized form corresponding to the one-center ("lone pairs") and twocenter ("bonds") elements of the chemist's Lewis structure.

The results of the NBO analysis have provided new insights into the Lewis structure, charge, bond order, bond type, hybridization, resonance, donor-acceptor interaction, etc. This is carried out by considering all possible interactions between the filled donor and empty acceptor NBOs and estimating their energy importance by second order perturbation theory.

The NBO analysis involving the hybridization of the selected bonds is performed at the B3LYP/LANL2DZ level and its results are summarized in Table 2.

The NBO calculated hybridization for 2,3-bis(furan-2-yl)pyrazino[2,3-f][1,10]phenanthroline demonstrates that the total hybridization of the molecule is $\mathrm{SP}^{\mathrm{X}}$, which is confirmed by the structural data.

\section{CONCLUSIONS}

In this work, the structure of the compound has been calculated and optimized by the DFT based method at B3LYP/LANL2DZ levels of theory, using the Gaussian 09 package of programs.

In this paper, some selected bond lengths and bond angles of the compound are obtained.

The comparison between the theory and the experiment is made. We thank the Research Council of Imam Khoemieni International University for supporting this work.

$\mathrm{T}$ a b 1 e 2

NBO Calculated Hybridizations for the compound

\begin{tabular}{c|c||c|c||c|c||c|c}
\hline Bond & Hybrid & Bond & Hybrid & Bond & Hybrid & Bond & Hybrid \\
\hline $\mathrm{C}_{1}-\mathrm{C}_{2}$ & $s p^{1.80}, s p^{1.61}$ & $\mathrm{C}_{4}-\mathrm{C}_{7}$ & $s p^{2.59}, s p^{2.05}$ & $\mathrm{C}_{15}-\mathrm{C}_{16}$ & $s p^{1.44}, s p^{1.99}$ & $\mathrm{C}_{23}-\mathrm{C}_{24}$ & $s p^{1.70}, s p^{2.22}$ \\
$\mathrm{C}_{1}-\mathrm{N}_{6}$ & $s p^{2.36}, s p^{1.73}$ & $\mathrm{C}_{7}-\mathrm{C}_{8}$ & $s p^{1.18}, s p^{1.99}$ & $\mathrm{C}_{15}-\mathrm{O}_{19}$ & $s p^{3.34}, s p^{2.42}$ & $\mathrm{C}_{23}-\mathrm{N}_{28}$ & $s p^{2.94}, s p^{1.82}$ \\
$\mathrm{C}_{2}-\mathrm{N}_{3}$ & $s p^{2.44}, s p^{1.83}$ & $\mathrm{C}_{8}-\mathrm{C}_{9}$ & $s p^{2.09}, s p^{2.05}$ & $\mathrm{C}_{16}-\mathrm{C}_{17}$ & $s p^{2}, s p^{2.51}$ & $\mathrm{C}_{24}-\mathrm{C}_{25}$ & $s p^{1.59}, s p^{1.82}$ \\
$\mathrm{C}_{4}-\mathrm{N}_{3}$ & $s p^{2.14}, s p^{1.83}$ & $\mathrm{C}_{9}-\mathrm{C}_{10}$ & $s p^{1.97}, s p^{1.44}$ & $\mathrm{C}_{17}-\mathrm{C}_{18}$ & $s p^{1.89}, s p^{2.52}$ & $\mathrm{C}_{25}-\mathrm{C}_{26}$ & $s p^{1.83}, s p^{1.77}$ \\
$\mathrm{C}_{4}-\mathrm{C}_{5}$ & $s p^{1.50}, s p^{1.79}$ & $\mathrm{C}_{10}-\mathrm{O}_{11}$ & $s p^{3.28}, s p^{2.69}$ & $\mathrm{C}_{18}-\mathrm{O}_{19}$ & $s p^{2.04}, s p^{2.43}$ & $\mathrm{C}_{32}-\mathrm{C}_{33}$ & $s p^{2.12}, s p^{1.87}$ \\
$\mathrm{C}_{5}-\mathrm{N}_{6}$ & $s p^{1.67}, s p^{1.85}$ & $\mathrm{C}_{7}-\mathrm{O}_{11}$ & $s p^{3.68}, s p^{2.25}$ & & & &
\end{tabular}




\section{REFERENCES}

1. Bencini A., Bernardo M.A., Bianchi A., Fusi V., Giorgi C., Pina F., Valtancoli B. // Eur. J. Inorg. Chem. - 1999. - P. 1911 - 1918.

2. Dong W.-X., Tong R.-R., Zheng C.-G. // Acta Crystallogr. - 2013. - E69. - P. o1613.

3. Li X.X., Guo Y., Chi H.J., Dong Y.Z., Hong B. // Mater. Chem. Phys. - 2001. - 123. - P. 289 - 292.

4. Sammes P.G., Yahioglu G. // Chem. Soc. Rev. - 1994. - 23. - P. 327 - 334.

5. Felber J.P., Coombs T.L., Vallee B.L. // Biochemistry. - 1962. - 1, N 2. - P. 231 - 238.

6. Smith M.C., Ciao Y., Wang H., George S.J., Coucouvanis D., Koutmos M., Sturhahn W., Alp E.A., Zhao J., Kramer S.P. // Inorg. Chem. - 2005 - 44. - P. 5562 - 5570.

7. Becke A.D. // J. Chem. Phys. - 1993. - 98. - P. 5648.

8. Lee C., Yang W., Parr R.G. // Phys. Rev. B. - 1988. - 37. - P. 785.

9. Hay P.J., Wadt W.R. // J. Chem. Phys. - 1985. - 82. - P. 270.

10. Hay P.J., Wadt W.R. // J. Chem. Phys. - 1985. - 82. - P. 299.

11. Reed A.E., Curtiss L.A., Weinhold F. // Chem. Rev. - 1988. - 88. - P. 899.

12. Gece G., Bilgic S. // Corros. Sci. - 2009. - 51. - P. 1876.

13. Glendening Ed., Landis C.R., Weinhold F. // WIREs Comput Mol. Sci. - 2012. 